\title{
When patients miss appointments, everyone pays
}

- Cite as: CMAJ 2020 February 10;192:E149-50. doi: 10.1503/cmaj.1095840

Posted on cmajnews.com on January 21, 2020

\section{Part one of a series on no-shows}

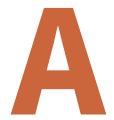

s resource pressures grow, health workers and officials in Canada and the United Kingdom are raising awareness about the costs of patients not showing up for appointments.

Last year, the UK's National Health Service revealed that a $5 \%$ no-show rate cost the system $£ 216$ million in a year, while a Nova Scotia family practice posted on Facebook that a single month of no-shows wasted 36 hours of physician time that could have been spent on other patients. But estimating the full impact of these missed appointments is complicated.

Tracking and reporting on the problem is not consistent in Canada, and the data that are collected suggest that no-show rates vary widely. Recent studies of four rural and urban academic family practices in Quebec and an inner-city clinic in Saskatchewan, respectively, reported no-show rates of $10 \%$ and $25 \%$. Older reports from Newfoundland and Labrador and Alberta cite no-show rates of $11 \%$ and 20-30\%, respectively.

The average no-show rate is about $23 \%$ internationally. Hospital clinics serving poorer populations tend to report higher rates while some family practices may report much lower rates. For example, Dr. Sohail Gandhi, president of the Ontario Medical Association, says the no-show rate at his Georgian Bay clinic is below $1 \%$.

Many doctors argue that patients not showing up for appointments drives up

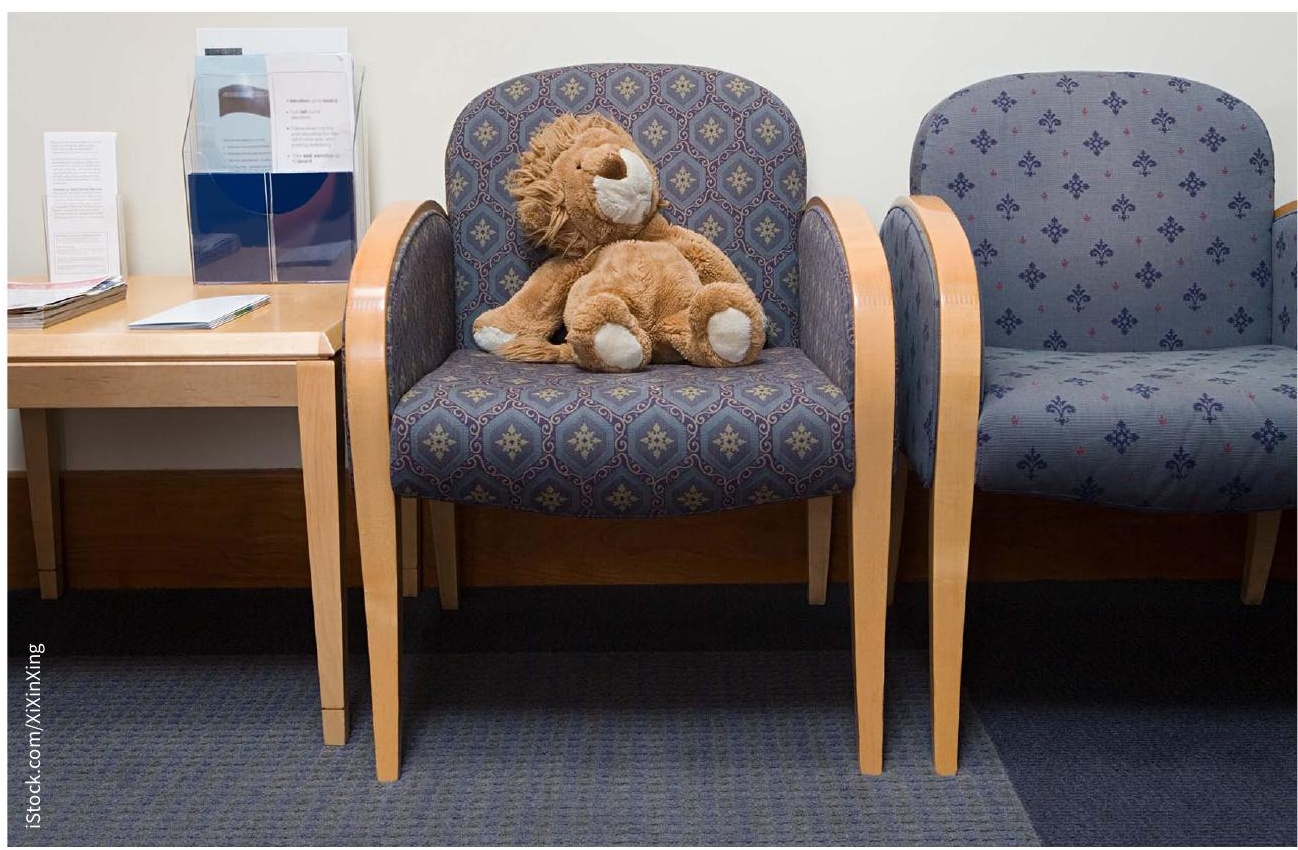

High rates of no-shows may drive up waits for care, warn doctors.

wait times. Dr. Andrew O'Keefe, an allergy specialist based in Newfoundland, says the $13 \%$ no-show rate at his clinic "increases our wait time by $13 \%$ longer than it needs to be."

Dr. Kathleen Ross, president of Doctors of BC, says that while her clinic's rate is much lower, at around $3 \%$ to $6 \%$, missed appointments still lead to delays. Often, discussions about no-shows focus on the overhead costs for doctors, she says. "But truly, for me, it's about maintaining access."

When it comes to access, no-shows are a double whammy, says Carol Sellar, manager of Health PEl's obstetrics and gynecology clinic. "The person who didn't show up is not getting the care they need, and it's also taking an appointment that could have gone to somebody else."

Costs can add up quickly, too. Although most doctors aren't paid for their time when patients don't show up, according to a 2016 review, some primary care networks in Alberta paid specialists more than $\$ 200$ per hour for no-show appointments.

Some clinics have found ways to reduce disruption from no-shows and late cancellations. At Sellar's clinic, for example, staff keep a list of patients who can fill appointment slots on short notice.

Dr. Amina Jabbar, a geriatrician who practises at Trillium Health Partners in 
Mississauga, Ontario, says the clinic where she completed her residency had a similar list. She cautions, however, that this strategy privileges patients who have easy access to transportation. Studies show that patients who miss appointments tend to be poorer and face barriers, such as transit issues, childcare obligations, and mental health and addiction issues.

"The patients who can't get there unless they have timely access to accessible transit, those are the patients we really want to see, because they're the most marginalized, versus the patients who can come at the drop of a hat. But at the same time, you're trying to figure out how do you maximize your capacity?" says Jabbar.

In her practice, patients don't show for appointments or cancel at the last minute about a fifth of the time. Jabbar tries to arrange to meet them at their home or the hospital, if they've been admitted, either immediately or within the week. She also uses the extra time from missed appointments to do paperwork. "It's usually not a big deal when somebody doesn't show up because I've got a backlog of stuff to finish up anyway," she says.

Often, patients have good reasons for missing appointments. The study of Quebec academic family practices found that most patients didn't show up for appointments because they felt better (22.9\%). Others cited work and family obligations ( $19.9 \%$ and $14.5 \%$ ), conflicting medical appointments elsewhere $(15.7 \%)$, transportation issues (15.1\%) and feeling too sick (13.9\%). More than half admitted they forgot to call to cancel, but one in 10 didn't know it was necessary and a similar proportion said it was impossible to reach anyone at the clinic.
St. Michael's Academic Family Health Team in Toronto serves a high proportion of low-income patients, as well as patients with mental health and addiction challenges, and takes a flexible approach to scheduling. Physicians often encourage patients who frequently miss appointments, or who are likely to face substantial obstacles, to show up when they can if they have a pressing need, according to Linda Jackson, senior clinical program director for primary and community care. Rostered patients who need to be seen urgently can also call for a same-day appointment or "walk in" to be seen by a doctor or nurse practitioner.

"The schedule is impacted by both people who show up who don't have appointments and people that don't show, so it balances itself out somewhat," says Jackson.

Wendy Glauser, Toronto, Ont. 